\title{
Cumulative Ductility and Hysteretic Behavior of Small Buckling-Restrained Braces
}

\author{
Hidajat Sugihardjo and Tavio \\ Department of Civil Engineering, Institut Teknologi Sepuluh Nopember (ITS), Surabaya, Indonesia \\ Correspondence should be addressed to Hidajat Sugihardjo; hidajat.sugihardjo@gmail.com
}

Received 3 March 2017; Revised 10 April 2017; Accepted 11 April 2017; Published 16 July 2017

Academic Editor: Luigi Di Sarno

Copyright (C) 2017 Hidajat Sugihardjo and Tavio. This is an open access article distributed under the Creative Commons Attribution License, which permits unrestricted use, distribution, and reproduction in any medium, provided the original work is properly cited.

\begin{abstract}
Cumulative ductility is defined as a ratio of total energy to elastic energy which is dissipated by an element of the structural system during cyclic loading. An element of the structural system is categorized hysteretic if the cumulative ductility factor fulfills certain criteria. This study investigated both analytically and experimentally Small Buckling-Restrained Braces (SBRBs). The core of bracings was modeled using Menegotto-Pinto and bilinear functions. The restrained bracing members were in the shape of square hollow steel section. They were made of the assembly of two L-shaped steel sections. From the experimental study on four SBRB specimens, it was proven that the proposed SBRBs have performed relatively stable hysteretic curves up to two percent of strain and the cumulative ductility factor of 199-450. This value is sufficient for the Buckling-Restrained Brace (BRB) elements as elastoplastic structural components. The comparisons of the hysteretic behaviors resulted by SBRB specimens using the MenegottoPinto functions and experiments exhibited good agreements, while the amount of energy dissipated by the SBRB specimens using the bilinear model agreed well with the experimental results. Based on the behavior of the experimental hysteretic, implementing the proposed SBRBs as components in ductile truss system is recommended.
\end{abstract}

\section{Introduction}

The Buckling-Restrained Brace (BRB) was initially named as an elastoplastic damper when it was first introduced. The bracing element was made of ductile flat bar embedded in the unbounded material in a tube for equalizing its tensile and compression strengths. The bracing has nonlinear behavior through dislocation of steel microstructure. It has the cross section of the element $(1, \mathrm{~A})$ as shown in Figure 1 [1]. The types of bracing sections composed of both unbounded material and assembled steel proposed by several researchers are shown in Figure 1 [2].

It can be seen in Figure 1 that the cross section of element $(2, B)$ was developed by Chen et al. [3], while the cross sections of elements $(1, D),(2, A),(2, C)$, and $(2, D)$ were investigated by Iwata et al. [4]. Figure 1 also illustrates the cross section of the element $(2, \mathrm{C})$ which was studied intensively by Shimokawa et al. [5] and Kamura et al. [6]. Sugihardjo [7] developed small type with the cross section $(2, \mathrm{C})$ and they were utilized as components in a ductile truss girder system.
After Kobe's earthquake in 1995, the use of low yieldstrength steel was rapidly developed in Japan, in which the members of these steels are LY100, LY160, and LY235. The low yield-strength steel was used as a bracing's core and inserted into a tube or other sections as a restrained member made of normal steel. The material has a yield stress of approximately 90 to $235 \mathrm{MPa}$ (up to one-third of A36), but its maximum strain can reach 1.5 to 2.5 times of the maximum strain of A36 steel [6, 8-10]. The use of low yield-strength steel as a substitute for normal steel is to ensure that the plastification would occur at low deformation and without significant changes in structural strength and further to ensure that it will produce high cumulative ductility $[5,8]$.

The use of BRBs as passive dampers in a ductile frame system has been studied extensively by many researchers [1114]. Erochko et al. [11] studied the comparative residual drift response of special moment-resisting frames (SMRFs) and BRB frames. The two systems showed similar peak drifts and drift concentration factors. However, the BRB frames experienced larger residual drifts than the SMRFs. When 
subjected to a second identical earthquake, both framing systems experienced larger-than-expected drifts when an initial drift greater than 0.5 percent was present. Another study [12] summarized that proper placement of BRBs in high-rise RC wall buildings reduced the shear forces along the height of the wall, the bending moment, and deformation demands at the midheight of the wall as well as the rotation and energy demands in the core wall significantly. The analytical study [13] on the thermal behavior of BRBs indicated that the failures of the cores and restraint members occurred as a result of both reduction in material strength and increase in compression stresses at elevated temperatures. Black et al. [14] concluded that the unbounded BRBs are the practical and reliable solutions to enhance the earthquake resistance of existing and new structures.

As the components of the ductile truss girder systems, the use of Small Buckling-Restrained Braces (SBRBs) was investigated intensively by several researchers. Based on the energy dissipation, the cumulative ductility factor of the proposed Buckling-Restrained Braced Truss-girder Moment Frames (BRB-TMF) subassemblages has met the requirements of the hysteretic system structure [7]. The design of BucklingRestrained Knee Braced Truss Moment Frame based on the Performance-Based Plastic Design results of a frame indicated excellent responses of all the inelastic deformations of the designated elements up to the target displacement levels [15]. A new design approach for Dissipative Truss Moment Frames can guarantee that all the dissipative devices located at the bottom-chord level reach their threshold resistances, preventing the yield of the members of the primary structural scheme [16].

In the current study, four SBRB elements were investigated analytically and experimentally. The SBRBs were the unbounded type and the bracing's cores were from flat-bar steel of A283 Grade C. The core has been treated by a soft annealing process in order to reduce its yield stress. As a restrained member of the core, the tube section was used. To make the tube of the element $(2, \mathrm{C})$, two angles of normal steel equivalent to A50 were assembled as can be seen in Figure 1 [7].

The main objective of this study is to further verify the previous experimental work conducted by Sugihardjo [7]. The cumulative ductility of SBRBs was investigated analytically using the Menegotto-Pinto functions [17] instead of the bilinear models as in the previous study, where the loading history was given until two percent of the strain [7]. These SBRBs would be implemented in a proposed structural system, that is, a Special Truss Moment Frame (STMF) from Goel and Itani [18] and AISC [19]. This frame was modified by replacing the $\mathrm{X}$-bracings with two SBRBs in order to increase the energy dissipation of the structural system $[7,20]$.

\section{Theory and Design of BRB}

The theory and design of BRB that represent behavior of real braces by considering the interaction between the core and the restrained member as well as the interaction between the strength and the stiffness of the restrained member were introduced by Inoue [21]. This concept is further adopted

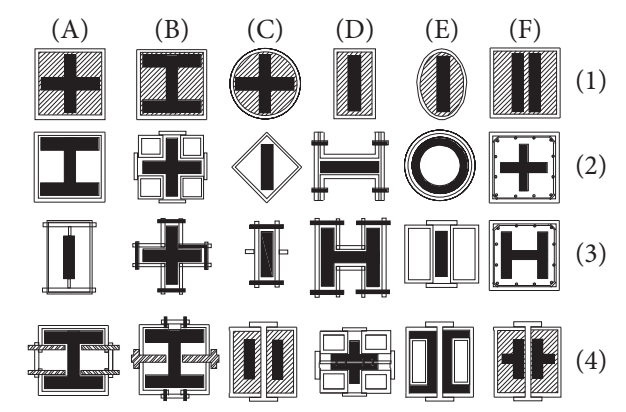

FIGURE 1: BRB sections proposed by several researchers [2].

in the current study. BRB was modeled as a flat bar which buckles at the middle of the bar due to compression load and interacts with elastic spring at the middle of the bar. The bar and the spring represent the core and the restrained member, respectively.

For the design purposes, (1) can be used to ensure that the bending moment occurs at the midlength of the restrained member and $M_{C}^{B}$ is less than its yielding moment capacity, $M_{y}^{B}$, where $N_{E}^{B}$ is the Euler buckling load of the restrained member; $N_{y}$ represents axial yield force of the core; $a$ is the amplitude of assumed half sinusoidal wave of initial deflection of the restrained member; $s$ is the total gap between the core and the restrained member; $e$ represents the excentricity of $N_{y}$ to its working line; and $E_{B} I_{B}$ is the flexural rigidity of the restrained member. The bending moment at the midlength of the restrained member due to the axial force in the core is contributed by the restrained member imperfection in the longitudinal direction (the first term in the bracket of the right-hand side of (1)) and the gap between the core and the restrained member as well as the eccentricity of the axial force in the core to its centerline axis (the second term in the bracket of the right-hand side of (1)). Equation (1) was derived from the differential equation of the elastic deflection curve due to the bending moment [21]. From the derivation of (1), it was obtained inequality in (2), where $L$ is the length of the core.

$$
\begin{aligned}
M_{C}^{B} & =\left\{\frac{a}{1-N_{y} / N_{E}^{B}}+\frac{s+e}{\cos \left((\pi / 2) \sqrt{N_{y} / N_{E}^{B}}\right)}\right\} N_{y} \\
& <M_{y}^{B},
\end{aligned}
$$

where

$$
\begin{aligned}
& N_{E}^{B}=\frac{\pi^{2} E_{B} I_{B}}{L^{2}}, \\
&\left(1-\frac{N_{y}}{N_{E}^{B}}\right) \frac{M_{y}^{B}}{N_{y} L}>\frac{a+s+e}{L} .
\end{aligned}
$$

If the parameters, flexural stiffness of restrained member and flexural strength of restrained member, of (2) are presented in the graphic form as the respective $x$ - and $y$-axes, (2) can, thus, be plotted in the form of interaction diagram shown 


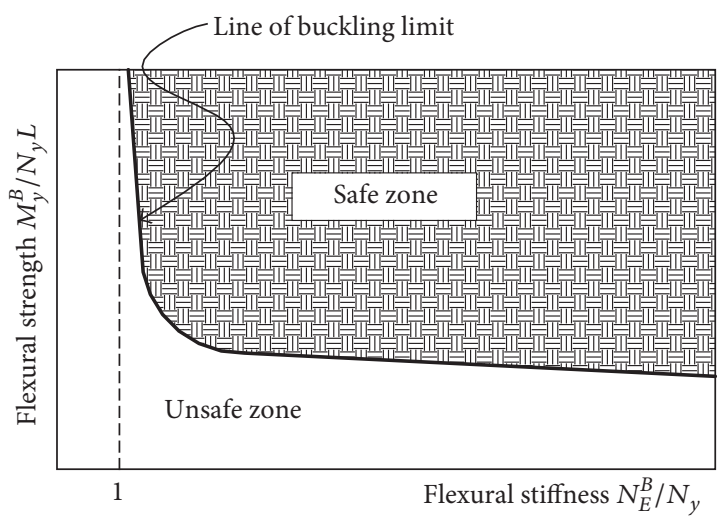

FIGURE 2: Interaction diagram for design of BRB [21].

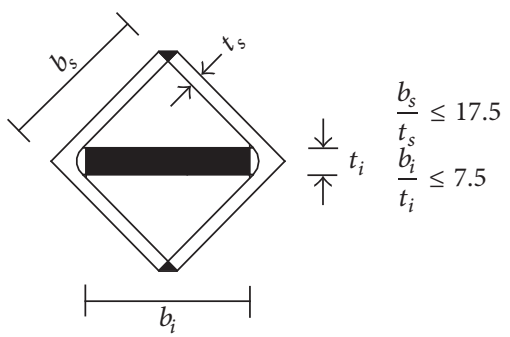

Figure 3: Compact section requirements for the BRB's dimensions [5].

in Figure 2. This figure shows that the design of BRB is a combination of the stiffness and the strength of the restrained member and its value must be located in the safe zone. Hence, this phenomenon indicated that the core acted as a damper did not buckle. On the other hand, it deformed inelastically. Other requirements to satisfy a stable hysteretic requirement are that the $\mathrm{BRB}$ must have the compact section which fulfills the criteria design given in Figure 3. The width-to-thickness ratio of the core and the tube must be less than 7.5 and 17.5, respectively [5].

\section{Analytical Model and Cumulative Ductility Factor}

3.1. Menegotto-Pinto Function and Bauschinger Effect. The model of SBRB element basically assumed that SBRB has equal axial capacity in tension and compression, in which its hysteretic model of material is extended from the multilinear and continuous monotonic models to represent Bauschinger effect as shown in Figure 4. The Bauschinger effect is a natural phenomenon of steel that has been stressed beyond its elastic limit and into the plastic range due to cyclic loading. In the cyclic $\sigma-\varepsilon$ diagram, it is illustrated by a tensile stress curve that initially has a sharp knee or discontinuity and further turns into continuous smooth curve after the stress reversal, and the shape continues for the next stress reversal. The transformation in shape from a sharp knee into continuous smooth curves is called the Bauschinger effect. It leads to a reduced hysteretic energy [17].

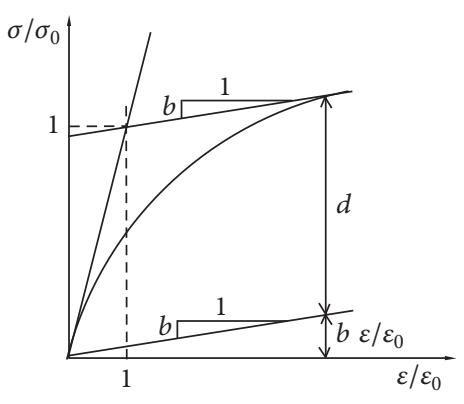

FIgURE 4: The Menegotto-Pinto material model for A283 steel [22].

To calculate stresses, $\sigma$, as a generalized function of strains, $\varepsilon$, the Menegotto-Pinto normalized function was adopted and it is expressed in

$$
\frac{\sigma}{\sigma_{0}}=b\left(\frac{\varepsilon}{\varepsilon_{0}}\right)+d=b\left(\frac{\varepsilon}{\varepsilon_{0}}\right)+\frac{(1-b)\left(\varepsilon / \varepsilon_{0}\right)}{\left[1+\left(\varepsilon / \varepsilon_{0}\right)^{n}\right]^{1 / n}}
$$

where $\sigma_{0}=E \varepsilon_{0} ; E=$ initial elastic modulus; $\varepsilon_{0}=$ initial strain; $\varepsilon=$ arbitrary strain; $b=$ ratio of the final to initial tangent stiffness (strain hardening parameter); $d=$ value, graphically defined in Figure $4 ; n=$ constant.

To use (3), the values of $\sigma_{0}, \varepsilon_{0}$, and $n$ must be evaluated. Graphically, from Figure $4, \sigma_{0}$ and $\varepsilon_{0}$ can be found by drawing the initial and final tangent to the data curves. The intersection of these two curves gives $\sigma_{0}$ and $\varepsilon_{0}$. The constant $n$ can be calculated by plotting $\varepsilon / \varepsilon_{0}=1$ [22]. In the numerical solution, the SBRB was modeled by a single strut element and was analyzed by using Seismosoft [17]. The Menegotto-Pinto function requires an initial shape parameter $R_{0}$ that controls the shape of the transition curve between initial and postyield stiffness to accurately represent the Bauschinger effect and pinching of the hysteretic loops. Furthermore, the function also requires coefficients $A_{1}$ and $A_{2}$ that calibrate the shape of the transition curve. These two parameters must also be applied to a parameter $R_{0}$.

3.2. Bilinear Model. As mentioned above, the study is carried out to verify the previous study by Sugihardjo [7] that adopted the bilinear hysteretic material to model SBRB element which was analyzed using DRAIN-2DX [23]. The core of SBRB was modeled as a truss element that has equal axial capacity in tension $\left(P_{y_{+}}\right)$and compression $\left(P_{y_{-}}\right)$. The material was modeled using the bilinear-elastoplastic material, and it was simplified by the omission of the Bauschinger effect and had a postyield stiffness, $E_{s}$, as shown in Figure 5.

3.3. Cumulative Ductility Factor. The cumulative ductility factor, $\eta$, which is defined as a ratio between total energy to elastic energy, can be estimated using (4) [24]. In (4), $W_{i}$ is energy on a cycle- $i$ while $P_{y}$ and $d_{y}$ are first yield force and first yield deformation, respectively. To fulfill the requirement 


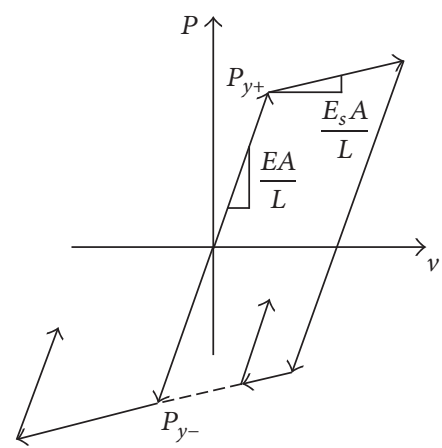

Figure 5: Truss element model with equal axial capacity in tension and compression $[7,23]$.

of a hysteretic structural element, the cumulative ductility factor of a BRB must be higher than 100 [5].

$$
\eta=\frac{\sum W_{i+}+\sum W_{i-}}{P_{y} d_{y}}
$$

\section{Experimental Study}

4.1. A283 Grade C Steel. The use of low yield-strength steels in Indonesia is uncommon, whereas this material is commonly used as BRB core. Therefore, in the current study the cores were made of ASTM-A283 Grade C produced by PT. Krakatau Steel. The cores have been treated by a soft annealing process with the objective to reduce its yield stress. This postannealing material has an average yield stress of $265 \mathrm{MPa}$ (306 MPa, for preannealing steel), the modulus of elasticity of $203,189 \mathrm{MPa}$, and the tangent modulus of $271.46 \mathrm{MPa}$ computed based on the slope of the $\sigma-\varepsilon$ curve in the plateau region as shown in Figure 6. Thus, the ratio of tangent modulus to modulus of elasticity is 0.139 percent.

4.2. Specimens and Tests. The cores were made of flat bars with two various dimensions of $50 \times 8 \mathrm{~mm}$ for SBRB-1 and SBRB- 4 and $40 \times 8 \mathrm{~mm}$ for SBRB- 2 and SBRB- 3 . The use of various dimensions has an objective to evaluate the behavior of SBRBs mainly when SBRBs are used as components of a ductile truss system. The restrained members were made of material equivalent to A50 steel. The cross sections of the tubes were assembled from two L-sections of $50 \times 50 \times 4 \mathrm{~mm}$ by welding.

The results of the design of four SBRBs as per requirements in Figure 3 and (2) are listed in Table 1. Column (7) of the Table 1 shows that the cores and the tubes satisfy the requirements as compact sections (Figure 3). By measuring the sections and tensile strengths of materials, the mechanical properties and dimensions of SBRBs were calculated and listed in Table 2. The values obtained from (2) by using the properties of SBRBs from Table 2 are shown in Column (8) of Table 1. All SBRBs meet the requirements of inequality of (2).

In the experiment, four SBRBs were made and tested. The schematic of the test setup was shown in Figure 7 where two LVDTs were installed at both sides of the specimen. Each specimen was loaded with loading history from $0.5,1.0$, and

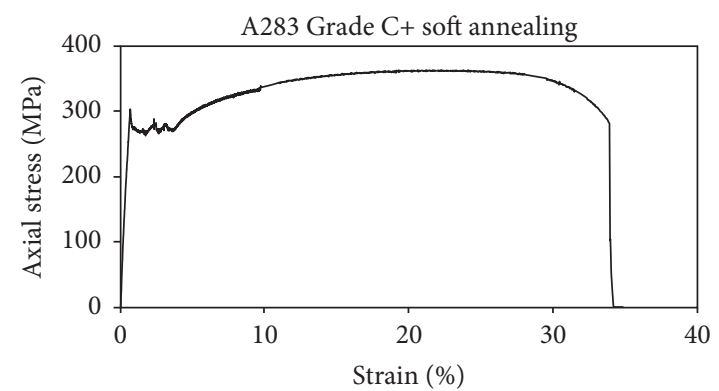

(a)

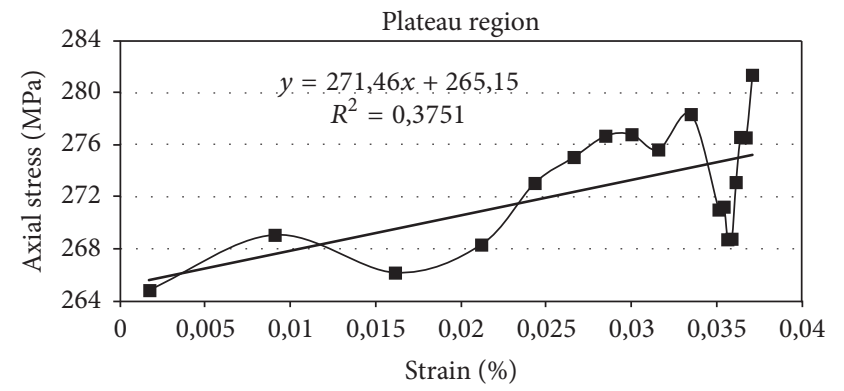

(b)

Figure 6: (a) $\sigma-\varepsilon$ curve for A283 Grade C steel. (b) The plateau region of $\sigma-\varepsilon$ curve [7].

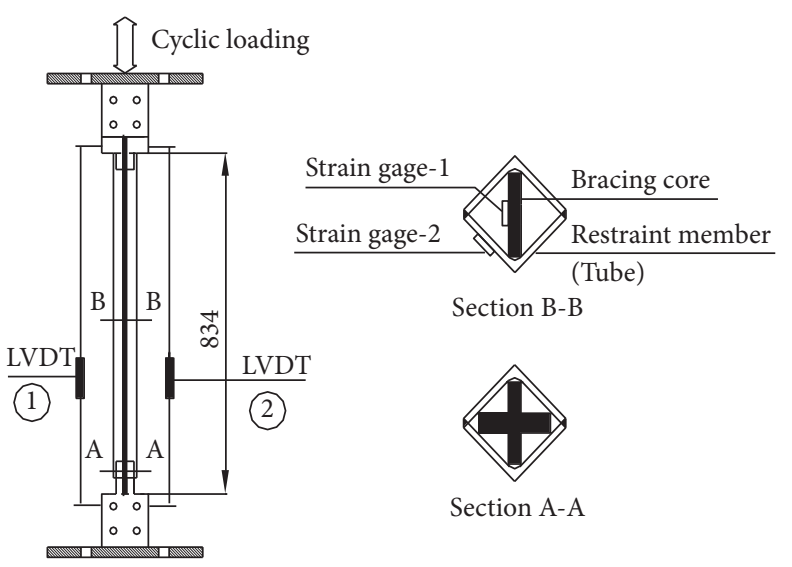

FIGURE 7: Schematic test setup and cross sections of SBRB [7].

1.5 to 2.0 percent of the strain (eight cycles) in which every step has two cycles as shown in Figure 8 (except that SBRB-1 was loaded up to three cycles with the strain of 1.5 percent due to a procedural error). The maximum strain of BRB was set up to two percent since the theoretical computation indicated that the predicted strain of SBRB was not greater than two percent as long as the SBRB is implemented in a ductile truss system [7]. Based on the two-percent strain, the cumulative energy and the energy per cycle of SBRBs were investigated both experimentally and analytically.

The cross section of SBRB at midlength and the setup of SBRB in the loading frame are shown in Figures 9(a) and 9(b), respectively. Figure 10(a) shows the cores of SBRBs welded in the truss system before being cased in the tubes and the 
TABLE 1: Dimensions of SBRBs from the design.

\begin{tabular}{|c|c|c|c|c|c|c|c|}
\hline $\begin{array}{l}\text { Specimen } \\
\text { (1) }\end{array}$ & $\begin{array}{c}\text { Width of core } \\
b_{i}(\mathrm{~mm}) \\
(2)\end{array}$ & $\begin{array}{c}\text { Thickness of core } \\
t_{i}(\mathrm{~mm}) \\
(3)\end{array}$ & $\begin{array}{c}\text { Width of tube } \\
b_{p}(\mathrm{~mm}) \\
(4)\end{array}$ & $\begin{array}{c}\text { Thickness of tube } \\
t_{p}(\mathrm{~mm}) \\
(5)\end{array}$ & $\begin{array}{c}\text { Length of core } \\
L(\mathrm{~mm}) \\
(6)\end{array}$ & $\begin{array}{l}\text { Criteria based on } \\
\text { compact section } \\
\text { Figure } 3 \\
\text { (7) }\end{array}$ & $\begin{array}{c}\text { Criteria based } \\
\text { on }(2) \\
(8)\end{array}$ \\
\hline $\begin{array}{l}\text { SBRB-1 } \\
50 \times 8\end{array}$ & 49.0 & 7.9 & 48.5 & 3.3 & 709 & $6.2<7.5$ and $14.7<17.5$ & $0.024>0.008$ \\
\hline $\begin{array}{l}\text { SBRB-2 } \\
40 \times 8\end{array}$ & 39.4 & 7.9 & 40.5 & 2.7 & 707 & $5.0<7.5$ and $15<17.5$ & $0.016>0.005$ \\
\hline $\begin{array}{l}\text { SBRB-3 } \\
40 \times 8\end{array}$ & 37.7 & 7.9 & 38.8 & 2.7 & 707 & $4.8<7.5$ and $14.4<17.5$ & $0.010>0.005$ \\
\hline $\begin{array}{l}\text { SBRB-4 } \\
50 \times 8\end{array}$ & 47.8 & 7.9 & 46.5 & 3.3 & 709 & $6.1<7.5$ and $14.1<17.5$ & $0.022>0.006$ \\
\hline
\end{tabular}

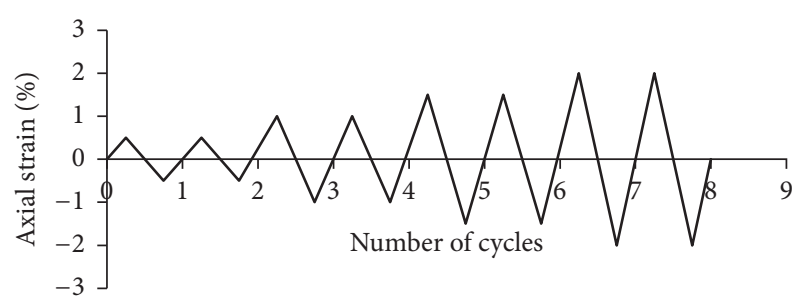

FIgURE 8: Loading history for SBRBs.

TABLE 2: Properties of SBRB sections.

\begin{tabular}{|c|c|c|c|c|}
\hline & SBRB-1 & SBRB-2 & SBRB-3 & SBRB-4 \\
\hline$\overline{f_{y}(\text { core })-\mathrm{MPa}}$ & 265.0 & 265.0 & 265.0 & 265.0 \\
\hline$A($ core $)-\mathrm{mm}^{2}$ & 387.1 & 311.3 & 297.8 & 377.6 \\
\hline$N_{y}($ core $)-\mathrm{N}$ & 102581.5 & 82483.9 & 78925.0 & 100069.3 \\
\hline$E$ (tube)- $\mathrm{MPa}$ & 214285.0 & 214285.0 & 214285.0 & 214285.0 \\
\hline$I($ tube $)-\mathrm{mm}^{4}$ & 113255.6 & 54069.7 & 47332.8 & 99372.8 \\
\hline$L($ core $)-\mathrm{mm}$ & 709.0 & 707.0 & 707.0 & 709.0 \\
\hline$N$ (tube-Euler)- $\mathrm{N}$ & 476012.6 & 228542.1 & 200066.4 & 417663.0 \\
\hline$b$ (tube)- mm & 48.5 & 40.5 & 38.8 & 46.5 \\
\hline$t$ (tube)- mm & 3.3 & 2.7 & 2.7 & 3.3 \\
\hline$b$ (core) $-\mathrm{mm}$ & 49.0 & 39.4 & 37.7 & 47.8 \\
\hline$t$ (core) $-\mathrm{mm}$ & 7.9 & 7.9 & 7.9 & 7.9 \\
\hline$Z$ (tube)- $\mathrm{mm}^{4}$ & 5123.9 & 2927.4 & 2678.8 & 4695.9 \\
\hline$f_{y}$ (tube)- $\mathrm{MPa}$ & 440.0 & 330.0 & 330.0 & 440.0 \\
\hline$M$ (tube-yield)-Nmm & 2254500.5 & 966047.2 & 884004.4 & 2066200.2 \\
\hline$a-\mathrm{mm}$ & 1.8 & 0.6 & 0.6 & 0.9 \\
\hline$s-\mathrm{mm}$ & 2.4 & 2.2 & 1.8 & 2.1 \\
\hline$e-\mathrm{mm}$ & 1.6 & 0.9 & 1.0 & 1.1 \\
\hline
\end{tabular}

assembled SBRBs as components of proposed BRB-TMF are shown in Figure 10(b) [7].

\section{Results and Discussion}

Imposing the cyclic loading history from Figure 8, the hysteretic curves for four specimens are given in Figure 11. These hysteretic responses were then compared with the corresponding analytical results using the Menegotto-Pinto model (plotted in the same figures). The model assumed the yield stress, modulus of elasticity, tangent modulus, and strain hardening parameter of $265 \mathrm{MPa}, 203,189 \mathrm{MPa}, 271.46 \mathrm{MPa}$, and 0.139 percent, respectively (based on Figure 6). Parameter $R_{0}$ and coefficients $A_{1}$ and $A_{2}$ were also set with the values of $20,18.5$, and 0.1 , respectively.

As can be seen in Figure 11, the maximum strains of SBRB-1, SBRB-3, and SBRB-4 reach two percent (elongation of $15.1 \mathrm{~mm}$ ). Meanwhile, the maximum strain of SBRB-2 reaches up to 1.5 percent (elongation of $10.1 \mathrm{~mm}$ ). SBRB-2 failed prematurely in the first cycle with only 1.5 percent strain due to poor welding process, whereas the other three SBRBs performed better as expected (up to two-percent strain with relatively stable hysteretic curves). Furthermore, from Figure 11, it can be observed that the hysteretic curves using the Menegotto-Pinto model are all in reasonably good agreement with the experimental results, even though the areas within the analytical hysteretic curves somewhat differ with the corresponding experimental curves at each cycle.

Figure 12 shows the comparisons between the hysteretic behavior from the experiments and the bilinear model using DRAIN-2DX [7]. The bilinear model also used the same material properties as those used in the Menegotto-Pinto functions, except that it did not require parameter $R_{0}$ and coefficients $A_{1}$ and $A_{2}$. If the hysteretic curves in Figure 12 are compared with those in Figure 11, it can be concluded that the Menegotto-Pinto functions with Bauschinger effect can predict the experimental curves better compared to the bilinear model.

Based on (4), the cumulative ductility factor of each SBRB specimen could be calculated by dividing total area of hysteretic curve by area of elastic curve of which results are shown in Column (7) of Table 3. In Column (4), it is shown that the hysteretic energy dissipated by SBRBs could be increased by increasing its axial stiffness. On the other hand, Column (7) of Table 3 shows that the increase of axial stiffness does not always increase the cumulative ductility factor. It mainly depends on the first yield load and the first yield deformation. All SBRBs have the cumulative ductility factor of 199 to 450 (greater than 100). Hence, the value is sufficient to satisfy the requirement that the BRB can be used as components of a hysteretic structure [5]. It is very important to notice that this value is higher than the 


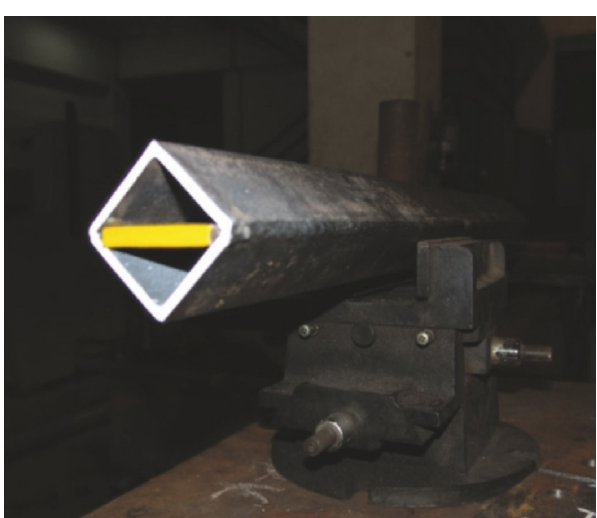

(a)

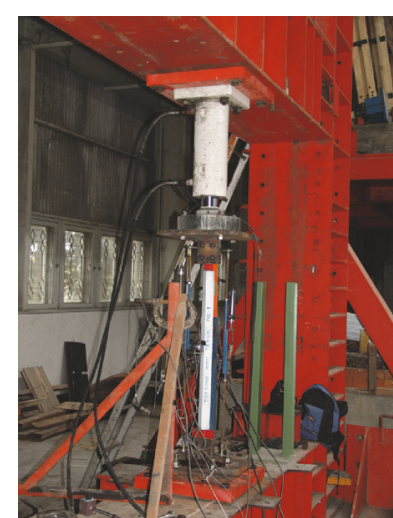

(b)

FIGURE 9: (a) Cross section of SBRB at midlength. (b) Setup of SBRB in the loading frame [7].

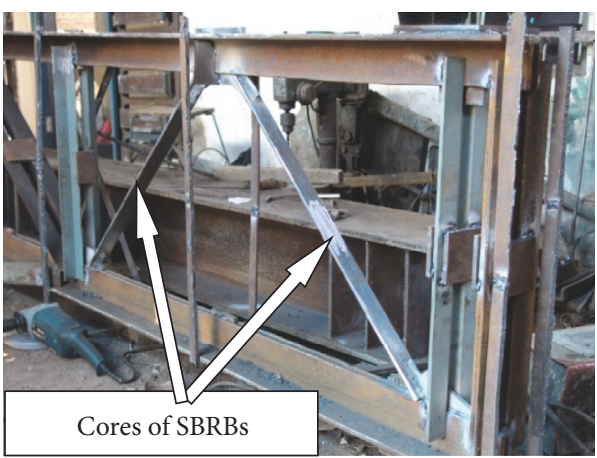

(a)

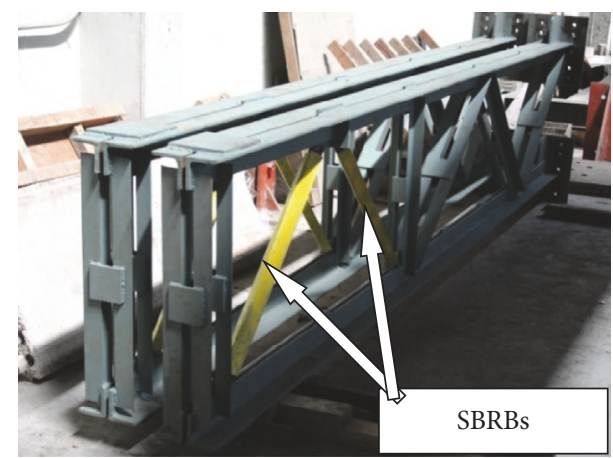

(b)

FIGURE 10: (a) The cores of SBRBs before being cased in the tubes. (b) SBRBs as components of BRB-TMF [7].

cumulative ductility factor reported by Sugihardjo [7] (166 to 377). The cumulative ductility factor obtained in that study has been reevaluated and found to be incorrect. This is due to the author's mistake in taking the starting and end points when calculating the experimental energy at each cycle.

The energy dissipation of each cycle and the cumulative energy of all SBRBs from the experiments then were compared with the analytical models using the Menegotto-Pinto functions and the bilinear using DRAIN-2DX as shown in Figure 13. It can be seen from Figure 13(a) that the cumulative energy of SBRB-1 using the Menegotto-Pinto functions is in good agreement with the experimental result, whereas the cumulative energies of SBRB-2 (neglecting the 8th-cycle), SBRB-3, and SBRB-4 using the bilinear model are in close agreement with the experiment results, as shown in Figures 13(b), 13(c), and 13(d), respectively.

From Figure 13 and Table 3, all four specimens show that the differences between the cumulative energies obtained from the analytical approach using the Menegotto-Pinto functions and the experimental results range from 4.0 26.0 percent, whereas the deviations of cumulative energies obtained using the bilinear model and the experimental results are in the range of $0.3 \sim 16.0$ percent. Thus, the cumulative energy differences using the bilinear model without taking into account the Bauschinger effects are smaller when compared to the cumulative energy differences using the Menegotto-Pinto functions. This phenomenon can be explained, from Figure 11, as follows: the reductions of energy areas of the experimental curves due to the Bauschinger effect are replaced by the excesses of energy areas due to the increase of the axial load capacity of each hysteretic loop. The increases of compression load capacities in the cyclic stressstrain curves are due to the increases of buckling modes of the bracing's core according to the sleeved column concept [25], which is not considered in the Menegotto-Pinto functions. Furthermore, from Columns (2) and (3) in Table 3, based on both analytical approaches, it can be observed that the Bauschinger effect reduces the cumulative energies dissipated by the bracing's cores made of flat-bar steel (A283 Grade C) which are ranging from 17 to 26 percent. Additionally, it was observed that the Menegotto-Pinto functions and the bilinear model did not consider the increase of the axial stress due to the increase of the axial strain after yielding in each cycle such as shown in the tests of the SBRBs. This phenomenon has caused the discrepancies between the cumulative energies obtained from both analytical models and those from the experiments.

It is very interesting to observe the deformed shaped of the SBRBs at the completion of the tests. In the design of SBRBs, it is required that the bending moment which occurs 


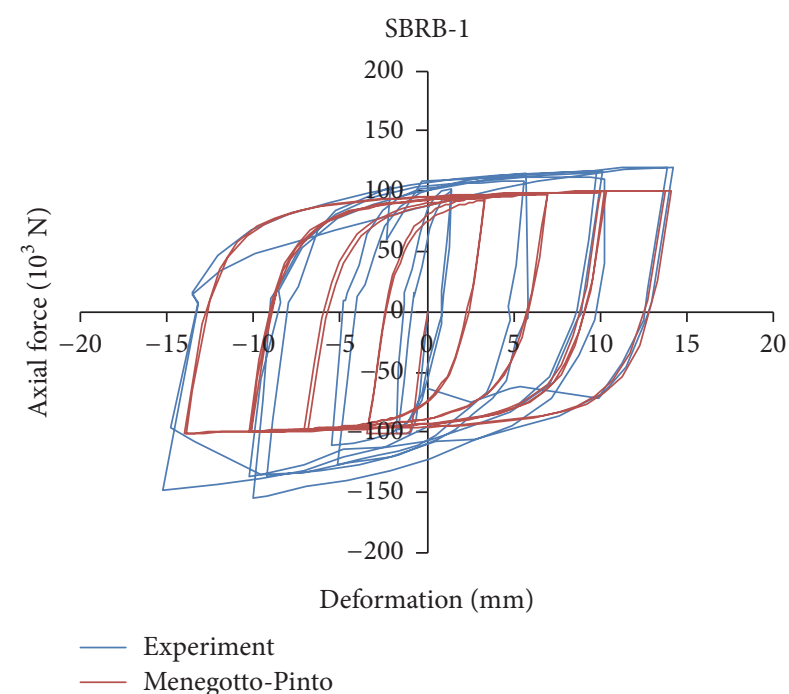

(a)

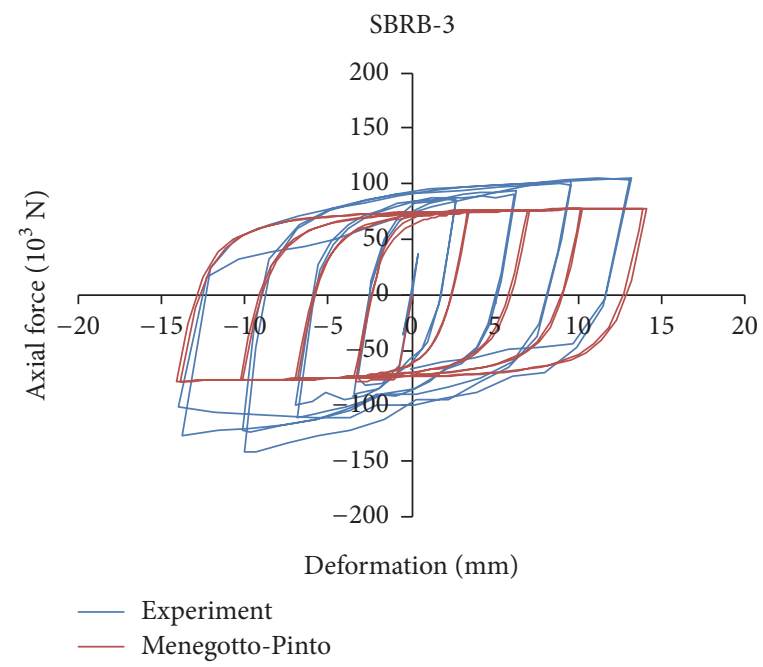

(c)

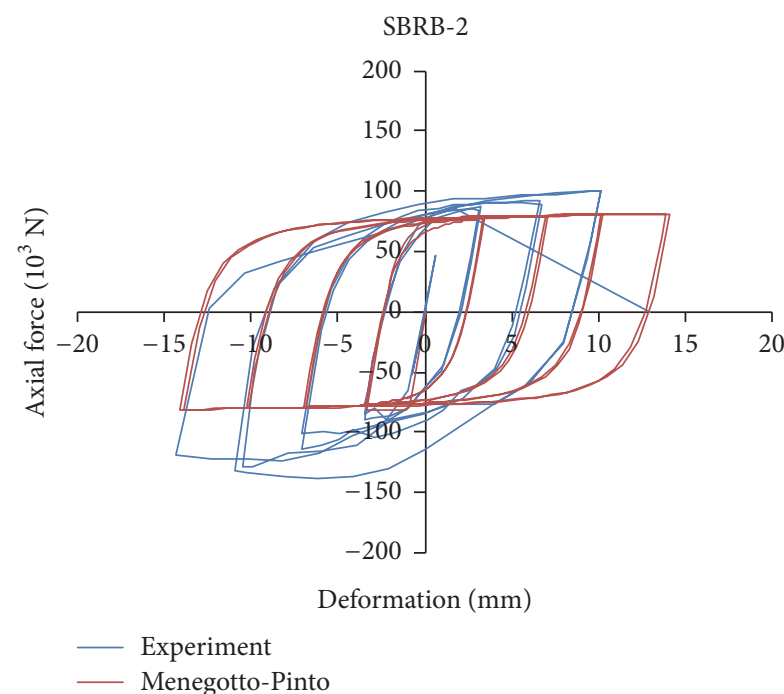

(b)

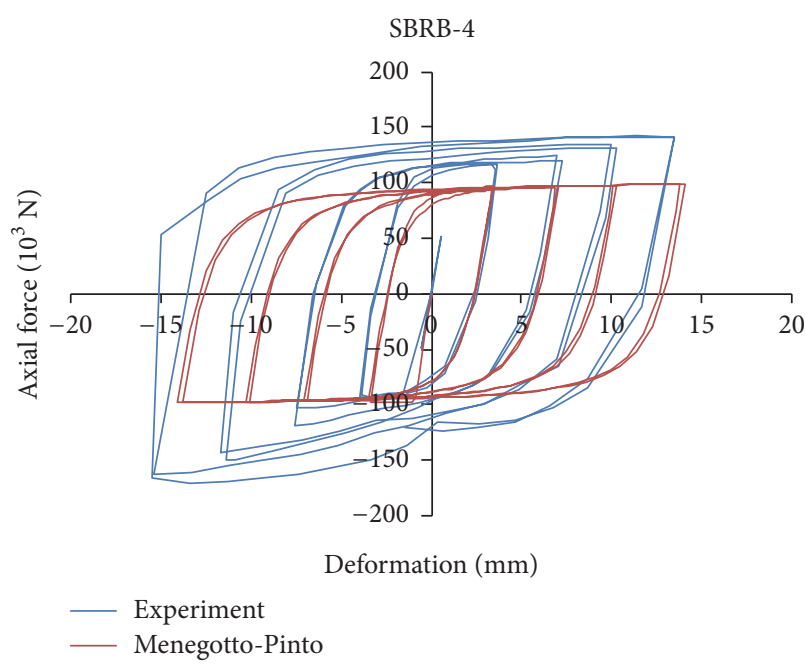

(d)

FIGURE 11: Hysteretic curves of SBRBs: experimental results by Sugihardjo [7] and analytical results using the Menegotto-Pinto functions [12] with steel core plates of (a) $50 \times 8 \mathrm{~mm}$; (b) $40 \times 8 \mathrm{~mm}$; (c) $40 \times 8 \mathrm{~mm}$; (d) $50 \times 8 \mathrm{~mm}$.

TABLE 3: Hysteretic energy and cumulative ductility factor $(\eta)$ of SBRBs.

\begin{tabular}{|c|c|c|c|c|c|c|}
\hline \multirow[t]{2}{*}{$\begin{array}{l}\text { Specimen } \\
\text { (1) }\end{array}$} & \multicolumn{3}{|c|}{$\begin{array}{c}\text { Hysteretic energy } \\
\sum W_{i} \\
\mathrm{kN}-\mathrm{mm}\left(\times 10^{3}\right)\end{array}$} & \multirow{2}{*}{$\begin{array}{c}\text { First yield force } \\
P_{y} \\
\mathrm{kN} \\
(5)\end{array}$} & \multirow{2}{*}{$\begin{array}{l}\text { First yield deformation } \\
\qquad \begin{array}{l}d_{y} \\
\mathrm{~mm} \\
(6)\end{array}\end{array}$} & \multirow{2}{*}{$\begin{array}{l}\text { Cumulative ductility factor } \\
\eta \\
(7)\end{array}$} \\
\hline & $\begin{array}{c}\text { Bilinear } \\
(2)\end{array}$ & $\begin{array}{c}\text { Menegotto-Pinto } \\
\text { (3) }\end{array}$ & $\begin{array}{c}\text { Experiment } \\
(4)\end{array}$ & & & \\
\hline SBRB-1 & 28.53 & 23.60 & 24.59 & 89.67 & 0.61 & 450 \\
\hline SBRB-2 & 19.51 & 15.47 & 14.08 & 65.66 & 0.92 & 233 \\
\hline SBRB-3 & 18.67 & 14.81 & 18.72 & 66.67 & 1.11 & 253 \\
\hline SBRB-4 & 23.67 & 20.19 & 27.52 & 90.90 & 1.52 & 199 \\
\hline
\end{tabular}

at midlength of the restrained member should not exceed its yielding moment (see (1)). In addition, the interaction value of the flexural strength and the flexural stiffness of the restrained member must fall in the safe zone (see Figure 2). Hence, the restrained members did not experience major deformed shapes as shown in Figures 14(a), 14(c), and 14(d). The cores of the SBRBs deformed axially only up to $15.1 \mathrm{~mm}$ (at the strain of 2 percent), so that the elongations of the cores did not appear extending out from the restrained members. An exception occurs on SBRB-2 which failed 


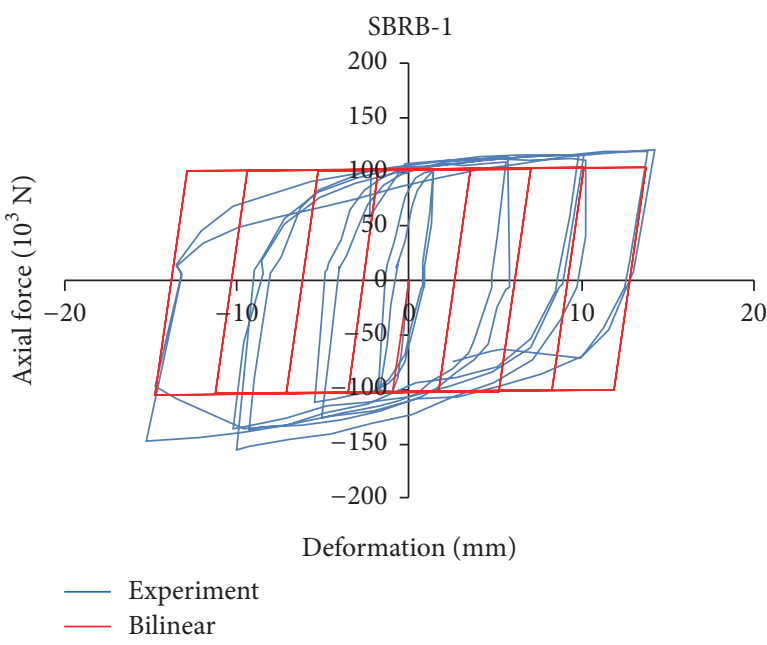

(a)

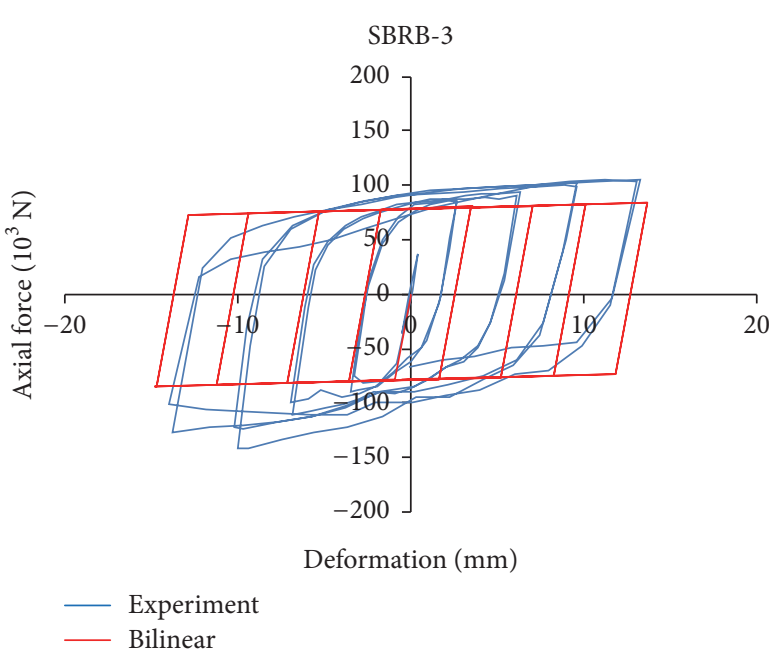

(c)

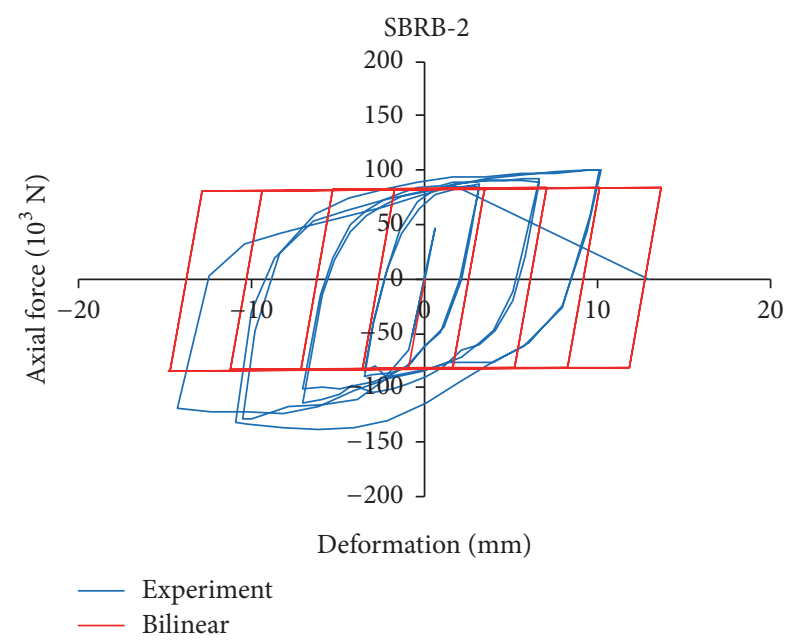

(b)

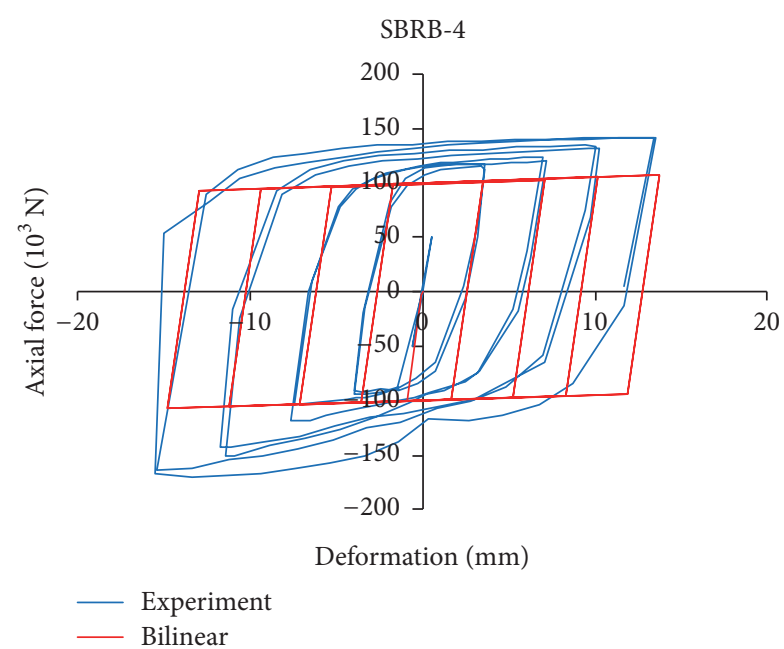

(d)

FIGURE 12: Hysteretic curves of SBRBs: experimental results and analytical results using the bilinear model with steel core plates of (a) $50 \times$ $8 \mathrm{~mm}$; (b) $40 \times 8 \mathrm{~mm}$; (c) $40 \times 8 \mathrm{~mm}$; (d) $50 \times 8 \mathrm{~mm}$ [7].

prematurely prior to reaching a strain of 2 percent. The restrained member experienced a premature local buckling. This can be addressed due to the poor welding work and the unforeseen axial eccentricity of the test setup of the SBRB-2 as shown in Figure 14(b).

\section{Conclusions and Recommendation}

The conclusions and recommendation of the current research can be drawn as follows:

(i) From the experimental work on SBRBs, it was proven that the proposed models have relative stable hysteretic curves up to two percent of the strain. This value is sufficient due to the fact that cumulative ductility factor (199 to 450) is greater than 100. This condition satisfies the criteria of SBRB as an elastoplastic structural element. (ii) The comparisons of the hysteretic curves of the SBRB specimens analyzed using the Menegotto-Pinto functions and those from the experiments exhibited reasonably close agreements.

(iii) The cumulative energies obtained using the bilinear models showed deviations to those obtained from the experiments in the range of $0.3 \sim 16.0$ percent, whereas the differences between the cumulative energies obtained from the analytical approach using the Menegotto-Pinto functions and those from the experiments are ranging from 4.0 to 26.0 percent. It can be concluded that the cumulative energies resulting from experiments agreed considerably well with those obtained by using the bilinear models.

(iv) For steel made of A283 Grade C which experienced soft annealing process, the contribution of the Bauschinger effect, analytically, has reduced the 


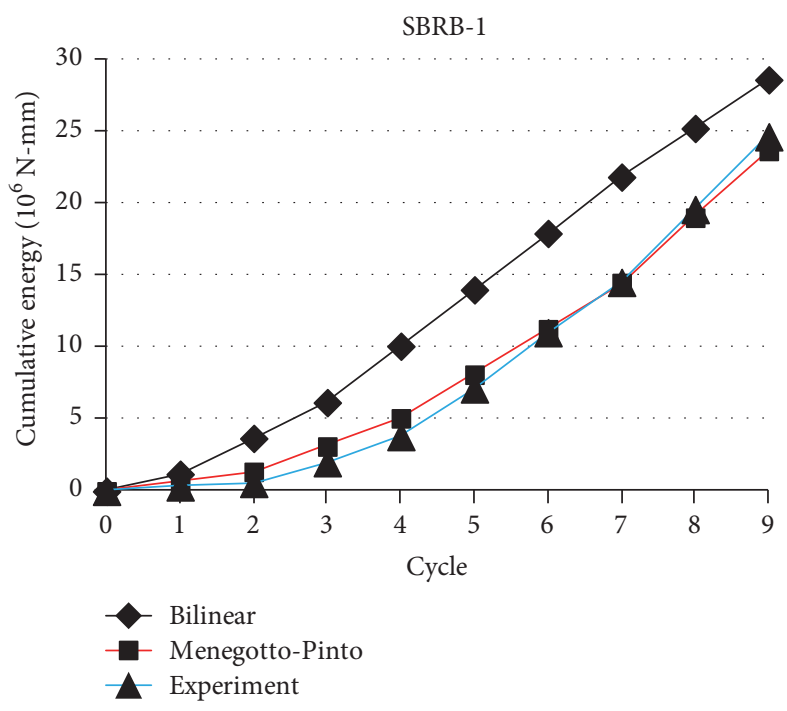

(a)

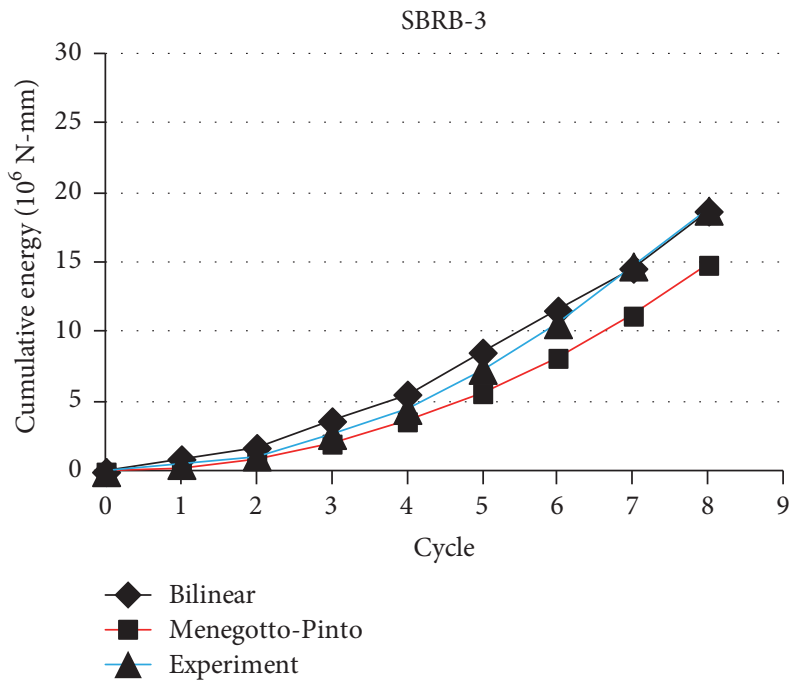

(c)

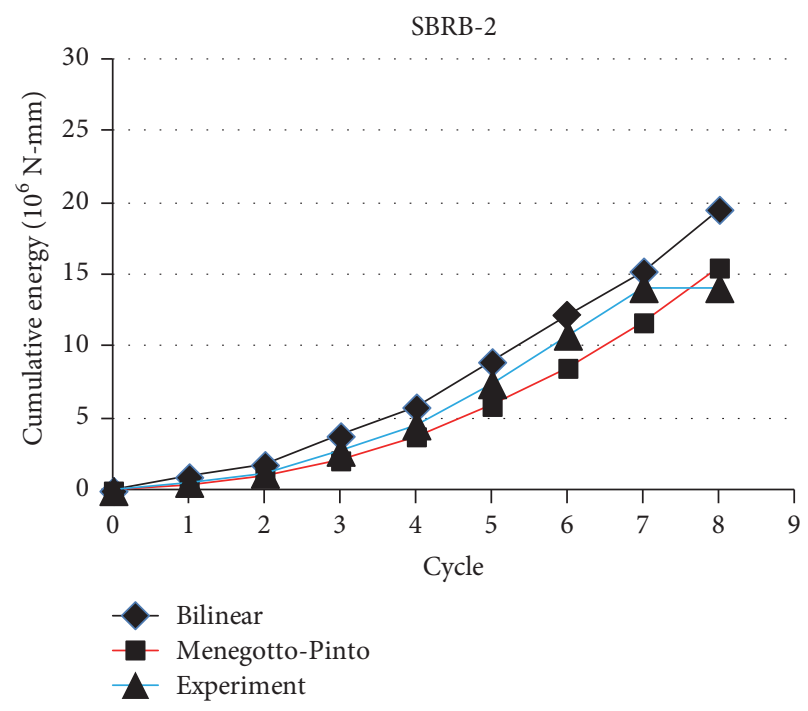

(b)

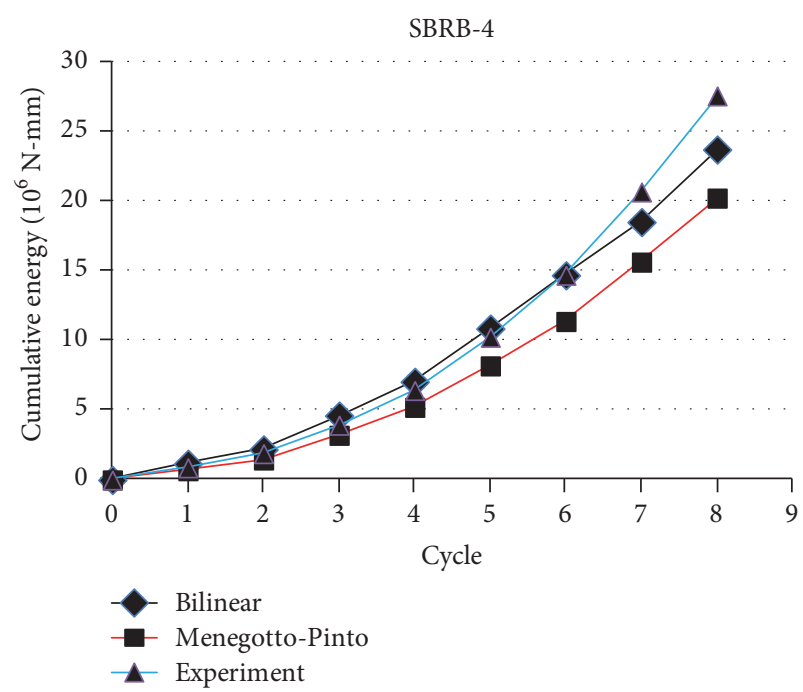

(d)

FIGURE 13: Comparisons of analytical cumulative energies by bilinear DRAIN-2DX, Menegotto-Pinto function, and experimental cumulative energy.

cumulative energies dissipated by the SRBBs (ranging from 17 to 26 percent).

(v) The hysteretic curves of SBRBs are relatively stable up to two-percent strain. Hence, implementing the proposed SBRBs as components of a ductile truss system is recommended. Analytically, the expected axial deformation of a SBRB is less than two percent (half of square root of two) for a drift ratio of a ductile truss system up to two percent.

(vi) To draw more accurate and representative conclusions, conducting more comprehensive experiments and investigations on the behaviors of the SBRBs is recommended.

(vii) In the future, coming up with a more accurate model for the SBRB is also suggested such that the model is able to better simulate the actual hysteretic behavior obtained from the experimental test.

\section{Conflicts of Interest}

The authors declare that there are no conflicts of interest regarding the publication of this manuscript.

\section{Acknowledgments}

The authors would like to convey their sincere gratitude to Widiadnyana Merati, Adang Surahman, and Muslinang Moestopo from Institut Teknologi Bandung, Indonesia, for all their constructive advices. Sincere thanks are also due to Nur Arifin from PT. Krakatau Wajatama, a subcompany of PT. Krakatau Steel, for his valuable contribution in providing 


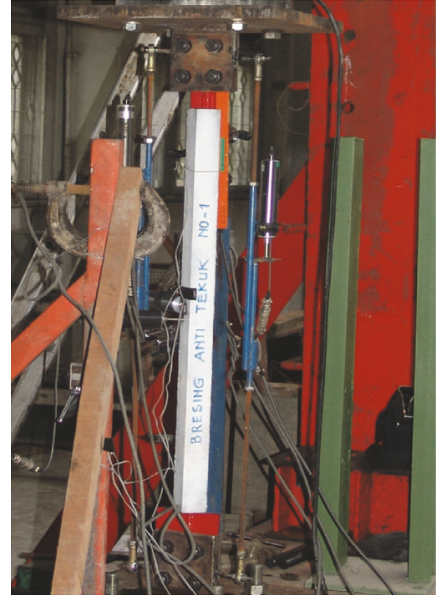

(a)

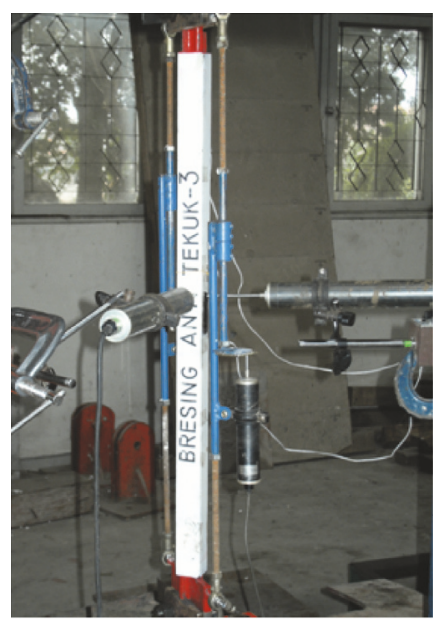

(c)

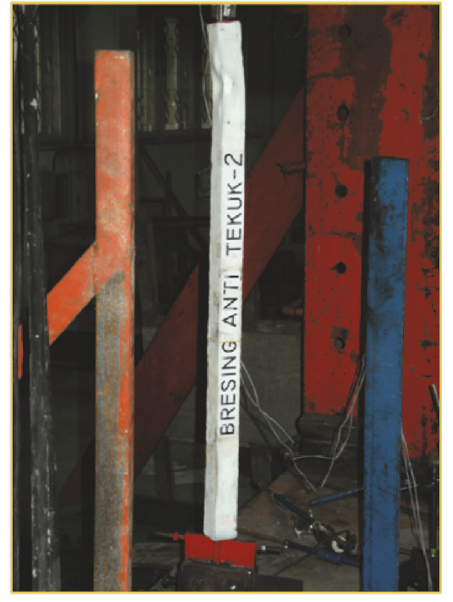

(b)

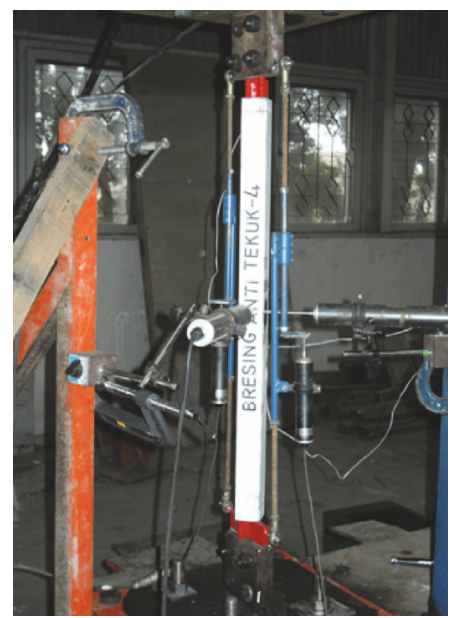

(d)

Figure 14: Deformed shapes at the completions of the tests (at strain of 2 percent): (a) SBRB-1; (b) SBRB-2; (c) SBRB-3; (d) SBRB-4.

the steel shapes and plates. The authors also like to thank Lutfi Faisal and Sutadji from the R \& D Center of Kimpraswil, Ministry of Public Works and Housing, Cileunyi, Bandung, for all the experimental facilities and supports provided.

\section{References}

[1] A. Watanabe, Y. Hitomi, E. Saeki, A. Wada, and M. Fujimoto, "Properties of brace encased buckling-restraining concrete and steel tube," in Proceedings of the 9th World Conference on Earthquake Engineering, vol. IV, pp. 719-724, Tokyo-Kyoto, Japan, 1989.

[2] K. C. Tsai, J. W. Lai, Y. C. Hwang, S. L. Lin, and C. H. Weng, "Research and application of double-core buckling restrained braces in Taiwan, Paper No. 2179," in Proceedings of the 13th World Conference on Earthquake Engineering, Vancouver, British Columbia, Canada, 2004.

[3] C.-C. Chen, S.-Y. Chen, and J.-J. Liaw, "Application of low yield strength steel on controlled plastification ductile concentrically braced frames," Canadian Journal of Civil Engineering, vol. 28, no. 5, pp. 823-836, 2001.
[4] M. Iwata, T. Kato, and A. Wada, "Buckling restrained braces as hysteretic dampers: behaviour of steel structures in seismic areas," in STESSA, pp. 33-38, A. A. Balkema, Rotterdam, The Netherlands, 2000.

[5] H. Shimokawa, S. Ito, H. Kamura, S. Morino, and J. Kawaguchi, "Hysteretic behaviour of flat-bar stiffened by square steel tube," in Proceedings of the Fifth Pacific Steel Structure Conference, pp. 711-716, Korea, 1998.

[6] H. Kamura, T. Katayama, H. Shimokawa, and H. Okamoto, "Mechanical property of low yield strength steel and energy dissipation characteristics of hysteretic dampers with low yield steel," in Proceedings of the US-Joint Meeting for Advanced Steel Structures, pp. 1-14, 2000.

[7] H. Sugihardjo, Inelastic Behaviour of Ductile Buckling-Restrained Braced Truss-Girders Frames as Component of Storey Buildings [Ph.D. thesis], School of Postgraduate, Institut Teknologi Bandung, Bandung, Indonesia, 2006.

[8] K. Inoue, "Low yield-point steel for steel dampers," in Steel Construction Today and Tomorrow, pp. 7-8, the Japan Iron and Steel Federation, June 2004.

[9] T. Katayama, S. Ito, H. Kamura, T. Ueki, and H. Okamoto, "Experimental study on hysteretic damper with low yield 
strength steel under dynamic loading," in Proceedings of the 12th World Conference on Earthquake Engineering, Paper No. 1020, 2000.

[10] M. Nakashima, "Strain-hardening behavior of shear panels made of low-yield steel. I: test," Journal of Structural Engineering, vol. 121, no. 12, pp. 1742-1749, 1995.

[11] J. Erochko, C. Christopoulos, R. Tremblay, and H. Choi, "Residual drift response of SMRFs and BRB frames in steel buildings designed according to ASCE 7-05," Journal of Structural Engineering, vol. 137, no. 5, pp. 589-599, 2011.

[12] M. Ahmed, S. Tayyaba, and M. W. Ashraf, "Effect of buckling restrained braces locations on seismic responses of high-rise RC core wall buildings," Shock and Vibration, vol. 2016, Article ID 6808137, 15 pages, 2016.

[13] E. Talebi, M. M. Tahir, F. Zahmatkesh, A. Yasreen, and J. Mirza, "Thermal behavior of cylindrical buckling restrained braces at elevated temperatures," The Scientific World Journal, vol. 2014, Article ID 672629, 15 pages, 2014.

[14] C. J. Black, N. Makris, and I. D. Aiken, "Component testing, seismic evaluation and characterization of buckling-restrained braces," Journal of Structural Engineering, vol. 130, no. 6, pp. 880-894, 2004.

[15] N. Wongpakdee, S. Leelataviwat, S. C. Goel, and W.-C. Liao, "Performance-based design and collapse evaluation of buckling restrained knee braced truss moment frames," Engineering Structures, vol. 60, pp. 23-31, 2014.

[16] A. Longo, R. Montuori, and V. Piluso, "Failure mode control and seismic response of dissipative truss moment frames," Journal of Structural Engineering (United States), vol. 138, no. 11, pp. 13881397, 2012.

[17] Seismosoft, "SeismoStruct v7.0-A Computer Program for Static and Dynamic Nonlinear Analysis of Framed Structures," 2014, http://www.seismosoft.com.

[18] S. C. Goel and A. M. Itani, "Seismic-resistant special trussmoment frames," Journal of Structural Engineering (United States), vol. 120, no. 6, pp. 1781-1797, 1994.

[19] AISC, Seismic Provisions for Structural Steel Building, American Institute of Steel Construction, Chicago, USA, 2005.

[20] H. Sugihardjo, "Earthquake-resistant building: buckling-restrained braced truss-girder moment frames (Proposed)," IPTEK, The Journal for Technology and Science, vol. 19, no. 1, pp. 24-44, 2008.

[21] K. Inoue, "Hysteretic-type vibrations dampers. design of hysteretic type dampers," in Steel Construction Today and Tomorrow, vol. 7, pp. 4-6, the Japan Iron and Steel Federation, June 2004.

[22] M. Bruneau, C. M. Uang, and A. Whittaker, Ductile Design of Steel Structures, McGraw-Hill, New York, NY, USA, 1998.

[23] V. Prakash and G. H. Powell, DRAIN-2DX, University of California, Berkeley, Calif, USA, 1992.

[24] H. Akiyama, Earthquake-Resistant Limit-State Design for Building, University of Tokyo Press, 1985.

[25] B. N. Sridhara, "Sleeved column as a basic compression member," in Proceedings of the 4th International Conference on Steel Structures and Space Frames, pp. 181-188, Singapore, 1990. 


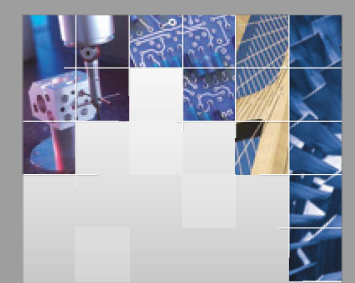

\section{Enfincering}
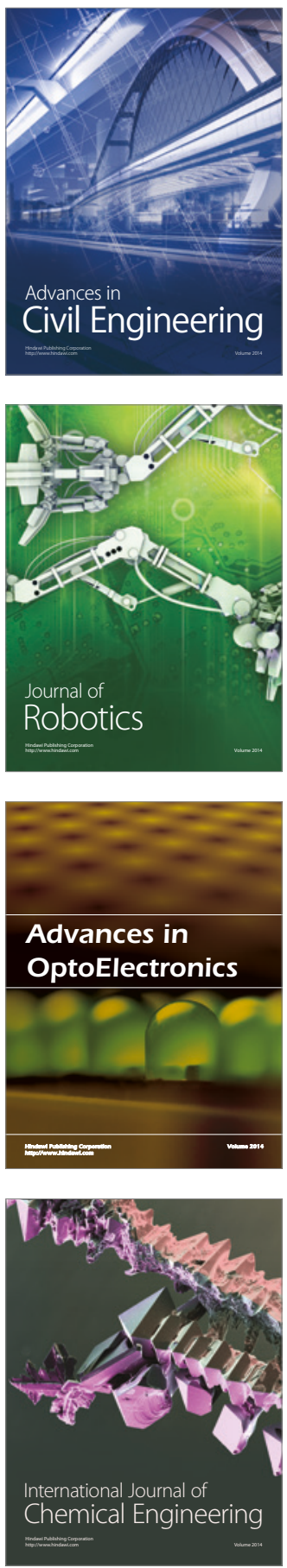

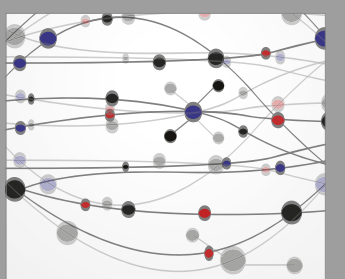

The Scientific World Journal

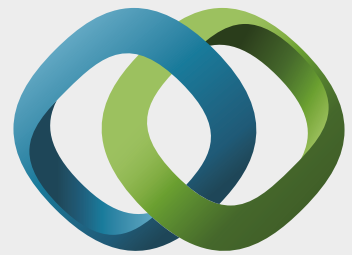

\section{Hindawi}

Submit your manuscripts at

https://www.hindawi.com
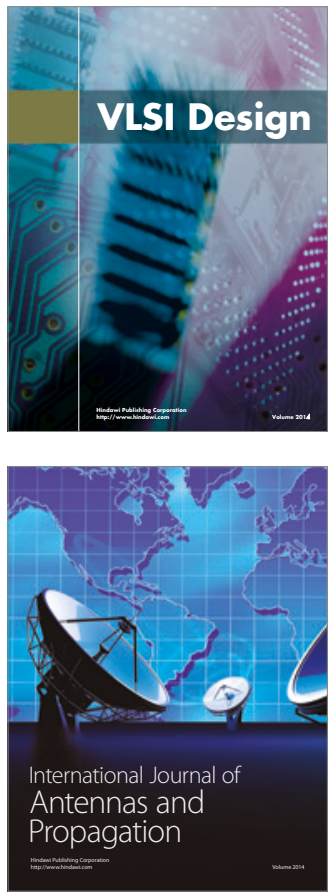

\section{Rotating}

Machinery
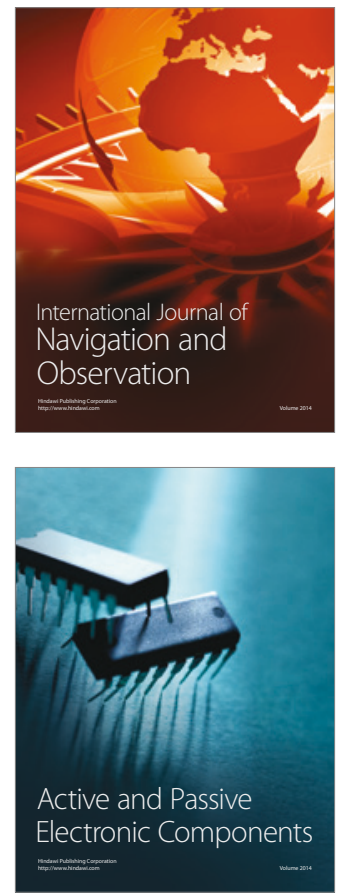
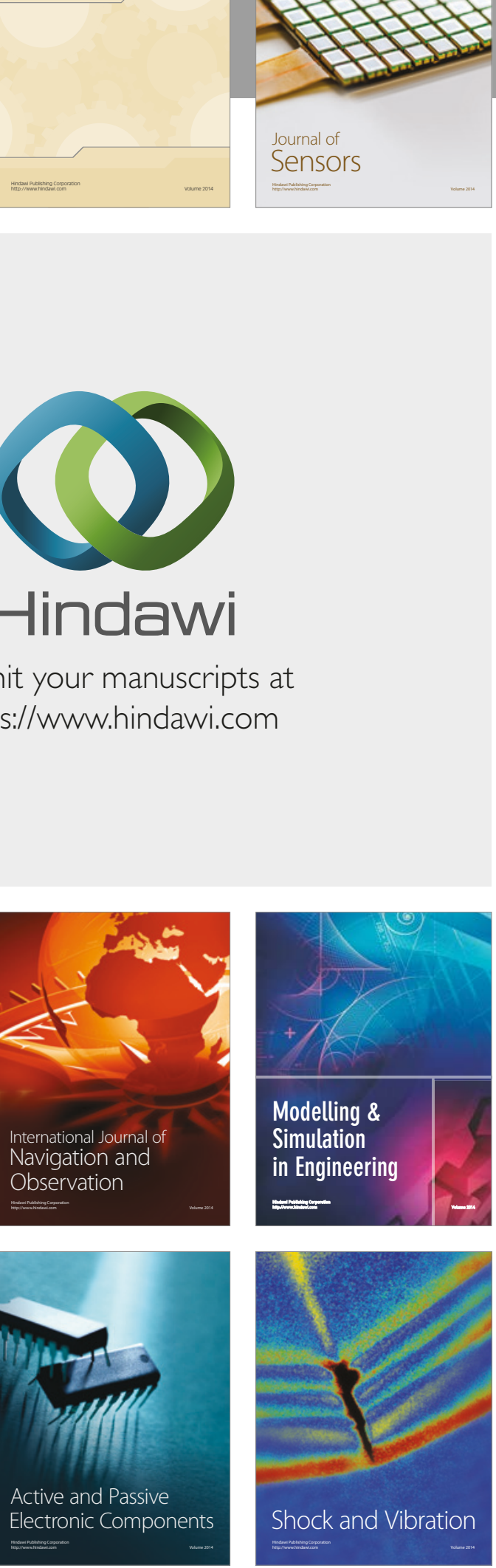
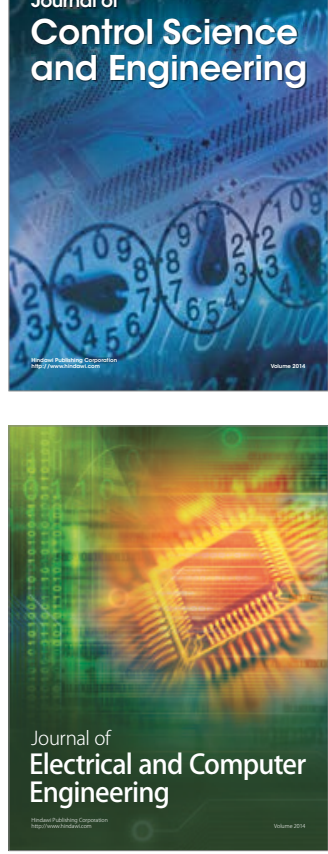

Distributed

Journal of

Control Science

and Engineering
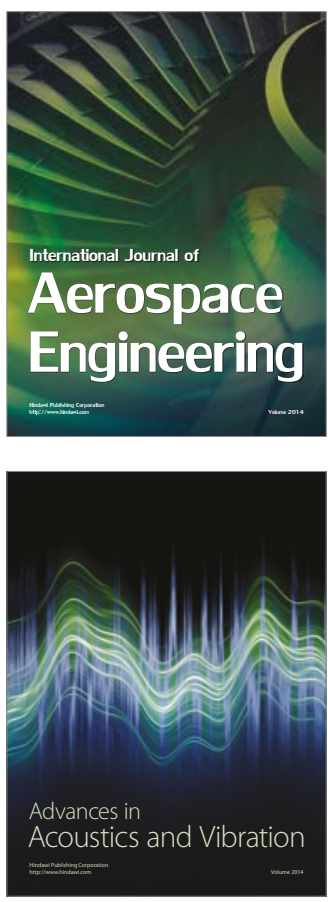

Sensor Networks 